\title{
Labour Mobility Options as Adaptation Strategies to Environmental Changes? \\ Elisa Fornalé ${ }^{1}$
}

\section{Introduction}

The international community has devoted a substantial effort to understanding the concrete impact of environmental degradation (defined as slow-onset environmental degradation, such as rising sea levels, increased salinization, desertification, and soil or coastal erosion) on human mobility and to fostering research to identify migration, in particular labour mobility, as a positive adaptation strategy. ${ }^{2}$ For example, the latest report of the Intergovernmental Panel on Climate Change (IPCC) focuses for the first time on human mobility, noting that:

climate change is projected to increase the displacement of people throughout this century. The risk of displacement increases when populations who lack the resources to migrate experience higher exposure to extreme weather events, in both rural and urban areas, particularly in low-income developing countries. Changes in migration patterns can be responses to both extreme weather events and longer-term climate variability and change, and migration can also be an effective adaptation strategy. ${ }^{3}$

In line with this statement, a major achievement of the 2012 Conference of the Parties to the UN Framework Convention on Climate Change (UNFCCC) (COP 18) was the adoption of paragraph 7(a)(vi) of the Draft decision -/CP.18, which links migration and the emerging issue of 'loss and damage' by acknowledging the need for further research and work towards 'enhancing the understanding of: [...] How impacts of climate change are affecting patterns of migration, displacement and human mobility. ${ }^{4}$ More recently, the adoption of the Paris Agreement in December 2015 established the creation of a new mechanism, the Task Force on Displacement, to 'develop recommendations for integrated approaches to avert, minimise and address displacement related to the adverse impacts of climate change. ${ }^{5}$ Over the course of the next two years, this Task Force will elaborate and identify innovative measures to address the impact of climate change, in particular human mobility from affected countries.

Equally, the outcomes of the Nansen Initiative's ${ }^{6}$ consultations in the Pacific, Central America, and the Greater Horn of Africa focused on the migration-environment nexus and reflect the scientific consensus regarding its reality, urgency and significance. ${ }^{7}$ The Nansen 
Initiative's Protection Agenda, adopted in October 2015, highlights several legal gaps related to cross-border displacement in the context of disasters linked to natural hazards, including critical issues such as 'admission, basic rights during the temporary or permanent stay, and conditions for return., 8

The European Commission has further situated the discussion within the context of migration law, as well as international law, suggesting that 'facilitating well-managed mobility and labour mobility from environmentally degraded areas can represent an effective strategy to reduce environmentally-induced displacement. ${ }^{9}$ Likewise, the Advisory Group on Climate Change and Human Mobility (hereinafter Advisory Group) has noted that 'voluntary migration, whether circular, temporary, or permanent, can be potentially positive form of adaptation to climate change. ${ }^{10}$ Although it is a global problem, the impact of climate change on human mobility will not be uniform within countries, and therefore it may be relevant to explore and identify different 'entry points' with a view to formulating appropriate and flexible strategies. ${ }^{11}$

In this regard, this chapter examines the potential of existing mobility options for reducing the vulnerability of affected communities by strengthening the nexus between human mobility regimes and climate-change related policies. In the past decade, a growing body of literature $^{12}$ has contributed to a broader conceptualisation of mobility by welcoming the idea that migration can be a legitimate 'adaptation strategy. ${ }^{13}$ In this context, the emerging debate on the environmental migration nexus relies on economic development and labour markets to foster resilience. ${ }^{14}$ Drawing from this approach, the chapter analyses the potential of existing avenues and tools which are available to facilitate mobility. The focus of the analysis will be on the case study of the Pacific Island Countries and the negotiations which have taken place in the context of trade-related measures to expand labour mobility channels. It appears crucial to explore what added value the progressive liberalisation of the temporary movement of natural persons as service suppliers can have for affected nations as a measure that can be used to complement traditional avenues of migration policy.

\section{Environmental Degradation and Mobility Strategies}

Slow-onset environmental degradation may generate diverse migratory outcomes: in some cases forced migration may occur for survival, whereas in others voluntary migration may be 
an efficient adaptation strategy. ${ }^{15}$ In particular, the estimates of actual and expected flows as a result of slow-onset environmental changes suggest that the pressure towards labour mobility across countries will increase. ${ }^{16}$

It is undisputed that individuals displaced across international borders as a result of environmental changes are especially vulnerable to human and economic losses and impacts, ${ }^{17}$ as well as to numerous protection and institutional gaps that arise because they do not have access to the same legal protection as other vulnerable groups. ${ }^{18}$ The Advisory Group recognises that 'migration can be a positive and survival strategy' and that there is a potential to improve the 'adaptive capacity' of affected communities by developing 'contextspecific solutions. ${ }^{19}$ Thus, facilitating and increasing labour mobility options can complement and support unilateral initiatives developed by states, on their own or as a group. $^{20}$

In this regard, Bettini et al highlight how the emerging discourse on the understanding of 'migration as adaptation' has to be re-oriented with regard to labour mobility to further explore the increasing potential to develop 'individualised' adaptation processes. ${ }^{21}$ In their analysis, they argue that the relationship between climate change and migration will contribute to shifting rights, duties and state responsibility regarding economic development and delegating responsibility to the labour market. ${ }^{22}$ In this new context they describe how the discourse around individual agency highlights that by securing access to the labour market, migrants increase their resilience. Conversely, the role of the state and international community is 'to govern the movement of labour migrants in order for them to undertake adaptation measures and secure themselves. ${ }^{23}$ In other words, the current debate provides an interpretation of 'migration as adaptation' that will no longer identify migrants as victims of environmental degradation but as 'agents of adaptation. ${ }^{24}$ Such an interpretation can help to understand how existing mobility regimes become strategic in their adaptation process. ${ }^{25}$

To complement this analysis, the aim of this chapter is therefore to explore the positive implications of conceiving migrants as a form of 'mobile labour power" ${ }^{26}$ and how existing instruments can be reconfigured to ensure that mobility regimes positively foster resilience and so indirectly protect human rights. ${ }^{27}$ 


\section{Human Mobility and Adaptation in the Pacific}

As part of this debate, the Pacific Island Countries (PICs) ${ }^{28}$ are becoming aware that they need to explore sustainable solutions to deal with issues linked with environmental degradation, such as increased unemployment. ${ }^{29}$ This is the case for instance for Kiribati and Tuvalu, which are particularly 'affected by climate change, and which cannot rely on domestic industries. ${ }^{30}$ Eberhard has emphasized that migration strategies have been widely and traditionally used by the citizens of low-lying states and, rather than focusing on statelessness, the contemporary debate needs to focus on how to remove obstacles for the legal admission of citizens of affected states to countries of destination, and how to secure their acceptance and integration in these countries. ${ }^{31}$

Moreover, the implementation of different migration schemes may play a relevant role in preventing forced displacement and in promoting voluntary movement from at-risk areas. ${ }^{32}$ As discussed further in this chapter, there is now a pluralised normative framework of labour mobility negotiations in the Pacific. The PICs are implementing and negotiating labour migratory instruments at the bilateral, regional and multilateral level and the following analysis will discuss the relevance of these instruments for individual countries. ${ }^{33}$ As recently stated by Kagan, 'not all Pacific island countries are created equal when it comes to employment creation. Some countries have natural resources that can drive respectable employment growth. Some have the right climate and conditions to attract tourists, even within a niche tourism market. Others have colonial connections that ensure some level of migration or trade with Australia, New Zealand and the US. ${ }^{34}$

In addition, some countries such as Kiribati recognise the need to enhance growth in entrepreneurial development of human capital to ensure that their citizens have the appropriate skills to contribute to the economy of their potential country of destination. ${ }^{35}$ The lack of adequate investment in skills development or qualifications may also affect the equal access of Pacific Islanders to different countries and labour markets. ${ }^{36}$

\section{a. Overview of Existing Labour Mobility Programmes}

Contemporary cross-border migration exhibits three main trends: i) from PICs to countries of the Pacific Rim (e.g. New Zealand and Australia); ii) migratory flows between New Zealand 
and Australia; and iii) intra-regional mobility between PICs. ${ }^{37}$ Migration has played a relevant role throughout the history of the Pacific region and it has taken many different forms but, as emphasized by Kagan, 'labour migration management remains underdeveloped' and the improvement of migration management has been identified as a regional and global goal to ensure decent work for migrants. ${ }^{38}$

This section highlights some of the main concerns and challenges to developing successful mobility programmes, and considers whether current mobility programmes can be adjusted to allow people affected by natural disasters, including environmental degradation, to move voluntarily from the affected settings.

First of all, there is a growing migration jigsaw formed by the different programmes and schemes in place, which can result in a fragmented normative environment and which can make the migration opportunities for citizens of PICs very different and unequal. Most of the existing migration schemes take the form of unilateral and voluntary commitments, meaning that 'migrant-receiving governments establish rules that employers must follow in order to receive permission to have legal foreign workers admitted. ${ }^{39}$ In these frameworks employers are gaining more and more control over administration of the schemes by asserting or attesting their need for foreign workers. In addition, as noted by Martin, these temporary or guest foreign worker programmes aim at rotating temporary workers in and out of the countries of destination without adding permanent residents to the population. ${ }^{40}$ In this context, the migration agreements developed by PICs with their neighbours, New Zealand and Australia, are of particular interest.

In 2007, New Zealand started the Recognised Seasonal Employer (RSE) programme that allowed the temporary entry of up to 8,000 persons annually to work in seasonal agricultural jobs. As stated by the New Zealand Department of Labour, one main objective of this programme was to 'encourage economic development, regional integration and good governance within the Pacific, by allowing preferential access to workers who are citizens of eligible Pacific countries. ${ }^{41}$ According to the World Bank, 24,600 workers have participated in this scheme, 'more than half of workers returned at least once, and 23 per cent of workers have participated in all seasons. ${ }^{42}$ Eligibility to this scheme is open to all countries, even if there is a Pacific preference. As remarked by Burson and Bedford, according to this scheme 'workers need to be recruited by New Zealand employers and the scheme is completely 
demand-driven. ${ }^{43}$ Recently, New Zealand decided to increase the annual cap from 8,000 to 9,500 people and this can be explained as a direct effect of the entry of Fiji into the RSE programme and of the impact of the PACER Plus negotiations, which will be discussed below. The percentage of Pacific workers recruited under this scheme increased from 74 per cent in 2009-10 to 85 per cent in 2014-15. ${ }^{44}$

In 2012, Australia started the Seasonal Worker Programme (SWP) in the horticultural sector after the completion of the Pacific Island Seasonal Worker Pilot Scheme (PSWPS). ${ }^{45}$ At first, 2,500 visas, and subsequently 3,250 visas, were made available for citizens from Papua New Guinea, Kiribati, Vanuatu, Tonga, Samoa, the Solomon Islands, Tuvalu, and Timor Leste for un-skilled temporary work, mainly in the horticultural industry. ${ }^{46}$ Participation in this scheme is exclusive to PICs citizens, with the addition of the Cook Islands and Niue who have automatic entry to New Zealand, as well as three Micronesian Forum Island Countries which have entered into free association with the United States.

In 2002, an interesting study designed by the World Bank with the New Zealand Department of Labour and the University of Waikato raised some specific concerns about how the RSE operates in practice. ${ }^{47}$ In particular, the survey highlighted a poor knowledge of the specific conditions of the temporary programmes, for example, about the obligations of employers. This concern has also been raised by the study conducted on the application of temporary schemes elaborated by Australia in which Hay and Howes identified a poor knowledge of these schemes. ${ }^{48}$ In addition, available data have revealed increasing obstacles to implementing these schemes for technical reasons. For instance, high transportation costs from specific Islands such as Vanuatu or Kiribati, may affect their citizens' ability to fully benefit from such schemes.

Speaking at the workshop attended by Pacific labour and trade officials in 2014, officials from the Ministry of Business, Innovation and Employment of New Zealand indicated that RSE is resource-intensive and costly and it would not be easy to extend it to other sectors. ${ }^{49}$ For this reason, it was suggested that there is a need to explore additional labour mobility opportunities that could make a more significant contribution to combining the needs of the Pacific island countries and industry labour.

Following on from this, significant progress has been registered by the Government of 
Australia, which adopted a White Paper in 2015 to remove existing caps on the number of migrant workers involved in temporary mobility schemes. ${ }^{50}$ This instrument builds on the reforms to expand Australia's SWP, recently announced by the government. In particular, from $1^{\text {st }}$ July 2015, Australia removed the national cap on the number of workers participating in the SWP. Access to this scheme is granted to all PICs, including the northern Pacific countries, Niue and the Cook Islands. Second, the White Paper proposed the establishment of a five-year pilot programme for 250 workers from Kiribati, Nauru and Tuvalu (around 50 workers per year). This five-year pilot programme will introduce a multiyear work visa to work in non-seasonal industries and occupations in Northern Australia.

With respect to the potential of these temporary programmes to deal with environmentallyinduced migration, it seems unlikely that such schemes provide the solution. The migratory challenges posed by these schemes are 'completely demand-driven.' There is no option in place for a potential Pacific worker to apply independently under one of these schemes; he or she has to be recruited by an employer. ${ }^{51}$ Also relevant is the absence of any option to transfer from temporary to long-term migration status in the country of destination. In this regard, the main countries of destination, such as Australia, could agree to foster labour mobility beyond the SWP, for instance by introducing a Pacific Access Quota, as proposed by the World Bank. ${ }^{52}$ The Pacific Access Category, adopted by New Zealand, reserves a special quota for citizens from small island states (including their partners and children) to encourage permanent labour mobility to New Zealand. ${ }^{53}$

\section{b. The Coverage of Temporary Movement of Natural Persons by Trade Agreements}

Since 1981, PICs have been involved in trade negotiations at the bilateral, regional and multilateral level. ${ }^{54}$ However, only recently has the issue of labour mobility begun to gain increasing relevance in the trade in services negotiation process. In fact, PICs are trying to increase and diversify the mobility options of their citizens by including specific coverage of 'temporary movement of natural persons' in a variety of trade agreements. ${ }^{55}$ This option could increase the number of opportunities available to cope with some of the impacts of climate change that are already happening. Even if no formal linkages are made between labour mobility and environmental degradation, such an agreement might provide a starting point for responding to mobility induced by environmental changes in the Pacific. 
As explained above, seasonal mobility schemes implemented by countries of destination, such as Australia and New Zealand, are limited. As highlighted by the Pacific Islands' Chief Trade Negotiator, Dr Edwini Kessie, the Pacific Islands are making specific demands to first increase the annual caps, and then extend these schemes to other occupations (e.g. care of the elderly, trade occupations, mining, seafaring, tourism). ${ }^{56}$

Of great relevance in this context was the negotiation process for the adoption of the Pacific Agreement on Closer Economic Relations (PACER Plus) between the PICs and Australia and New Zealand. The PICs identified labour mobility as a key priority. ${ }^{57}$ As argued by the Office of the Chief Trade Adviser (OCTA) 'due to the economic differences between the parties and the fact that FICs (Forum Island Countries) stood to gain very little, if at all, from their liberalisation commitments in trade in goods, services and investment, PACER Plus had to contain substantive commitments on labour mobility and development assistance. ${ }^{58}$ Edwini Kessie has noted that to address the concerns raised by the Government of Fiji: 'Both Australia and New Zealand have undertaken commitments which should facilitate the movement of skilled and semi-skilled workers in the PACER Plus area. ${ }^{59}$ The OCTA subsequently made a presentation in June 2016 during the Sixth Non-state Actors dialogue on the current status of PACER Plus negotiations with a focus on labour mobility to reiterate the potential of this process to reach reciprocal advantages and to facilitate the adoption of new forms of labour mobility. ${ }^{60}$

Indeed, as highlighted by Oxfam, a key element for PICs regarding labour mobility for migrant workers under PACER Plus was the inclusion of binding obligations that will prevent Australia or New Zealand from unilaterally terminating these arrangements as could be the case for seasonal schemes. In fact as highlighted by Kelsey, 'existing commitments on mode 4 and labour mobility show there are very limited precedents for binding and enforceable rights of access from the Pacific Islands, and none for workers with low skills or education. ${ }^{61}$

A key question during the negotiations was whether the coverage of temporary movement of natural persons would include labour mobility for unskilled workers. Even if formal commitments under Mode 4 of the General Agreement on Trade in Services (GATS) in free trade agreements (FTAs) are traditionally confined to categories of high-skilled services 
suppliers, there are some interesting precedents in recent FTAs concluded by Australia and New Zealand. In particular the Association of Southeast Asian Nations (ASEAN)-AustraliaNew Zealand FTA (2010) which incorporates semi-skilled and technical workers by including the category of 'installers and services. ${ }^{62}$

Furthermore, an interesting model is provided by the China-New Zealand FTA (2008) where commitments on temporary movement are contained in two separate annexes: the Annex on Temporary Employment Entry of Natural Persons and the Annex on Temporary Movement of Natural Persons, which provide opportunities to enter New Zealand for employment purposes in addition to the opportunities provided under New Zealand's immigration policy. ${ }^{63}$ In this agreement, categories of service suppliers include semi-skilled workers as well as skilled workers. Even if there is no agreed definition of this distinction, it is important for PICs to ensure that access to New Zealand and Australia's labour markets is not only offered to skilled migrants but also to lower skilled service providers.

The coverage of the temporary movement of natural persons has also been included in the negotiations of the Pacific Island Countries Trade Agreement - Trade in Services to increase labour mobility and skills transfer in the region (PICTA TIS). PICs agreed to draft and adopt a protocol for the temporary movement of natural persons (TMNP Protocol) which was opened for signature in $2012 .^{64}$ This protocol covers the temporary mobility of highly skilled (Tier 1) and skilled and semi-skilled workers (Tier 2) with temporary employment for up to three years. ${ }^{65}$ As argued by the Observatory on Migration (ACP), this regulatory framework has the potential to increase circular mobility in the region by contributing to the establishment of a single regional labour market. ${ }^{66}$ Migration patterns will therefore be impacted both by the use of this agreement to reduce barriers to free movement in the region and by turning vulnerable populations into agents of development in their area of origin. ${ }^{67}$ This agreement could thus assist in reducing vulnerability and enhancing the adaptive capacity of those faced with environmental degradation.

Nevertheless, as highlighted by the Report of the ACP Observatory on Migration, this scheme does not provide a comprehensive response to the 'protection gaps' raised by environmental-induced migration. First, this model can facilitate the temporary mobility of skilled migrants but it cannot be converted into permanent residence. Second, the TMNP Protocol attempts to address social security issues, but additional steps need to be taken at the 
bilateral level to draft and implement social security regimes. Finally, this scheme requires both the country of origin and the country of destination to play an active role and many countries of origin have no provisions in place to deal with mobility of skilled labour. In addition, the Pacific Island Forum Secretariat recommends the inclusion in PICTA of the provisions and standards available at the international level to protect migrant workers' rights under the International Labour Organization (ILO) Convention and the United Nations Convention on Migrant Workers and Member of Their Families. ${ }^{68}$

Finally, to conclude this overview, it is significant to recall that in 1993 the Melanesian Spearhead Group (MSG) ${ }^{69}$ adopted a regional trade agreement. This was followed in 2012 by the Skills Movement Scheme (SMS) Memorandum of Understanding, which covered the mobility of skilled workers. The purpose of the SMS is to:

- strengthen regional cooperation and integration by providing access to employment opportunities and to facilitate the movement of Melanesian Spearhead Group (MSG) nationals among the Parties;

- $\quad$ ensure and promote decent work practices amongst the Parties, and;

- bring mutual benefits to the Parties by the movement of skilled nationals. ${ }^{70}$

This instrument has been recognised as the first 'intra-regional mobility scheme, ${ }^{71}$ and allows up to 400 citizens of committed members to temporarily move to another member state for work reasons. ${ }^{72}$ Even if its relevance in the region has been defined as more 'symbolic than substantive' because of its low impact, it can be used as a frame of reference to improve the architecture of labour mobility at the inter-regional level and to meet skill shortages.

The Melanesian Spearhead Group Skills Movement Scheme's Memorandum of Understanding contains some inspiring provisions. Clause 6.2 of the MOU requires Parties to develop and adopt transparent, reasonable and impartial criteria for its implementation. A specific provision, Clause 9.11, calls for implementation of the principle of nondiscrimination in facilitating the entry and the stay of migrant workers. Clauses 12.1-2 require each party to apply international human rights and labour protection standards. Finally, spouses of migrant workers have a right to work in the same country in their specific 
occupation, according to national law.

\section{Conclusion}

This analysis has provided a brief introduction to existing migration agreements in the Pacific region to explore the potential of migration as adaptation strategy to gradually respond to environmental degradation. Concentrating on the mobility schemes developed by small island states, this chapter shows a clear lack of comprehensive instruments able to provide specific responses in this context. The normative scenario is highly fragmented and the current migration programmes will need to be revised to address some persisting limits that risk impeding the mobility of potential environmental migrants. Temporary mobility schemes, such as seasonal programmes, remain the most widely adopted schemes for facilitating labour mobility, but challenges persist in consolidating them with Australia and New Zealand and to translate them into binding agreements. For instance, the mechanisms in place will benefit from the progressive flexibility in allocating quotas, as in the case of the new programme launched by the Government of Australia. The core rationale of these schemes is to rotate foreign workers in and out to fill vacant jobs without allowing these workers to become 'free agents' in the labour market, and this is a major factor in the inadequacy of these instruments to increase adaptation efforts of affected population. In fact, the schemes in place show how employers have made decisions on how and whether to recruit migrants beyond a country's borders.

In addition, the focus on labour mobility in the PACER Plus negotiations, together with the TMNP Protocol, may provide an effective framework to foster the mobility of skilled service providers across the region. If the limitation on expanding the cross-border mobility of less skilled workers within the PACER Plus negotiations remains, this will require the design alternative specific new migratory mechanisms. Given the persisting challenges of existing mechanisms to absorb environmentally-induced mobility, a key element in re-tooling or designing migratory schemes is to ensure that in the future the concerns and priorities of affected populations will gain a prominent role in the development of the international agenda.

\footnotetext{
${ }^{1}$ The author acknowledges the support of the Swiss National Foundation Research, grant no. PP00P1163700. The chapter is based on the KNOMAD Working Paper 'The Future Role of Labour Mobility Mechanisms in the Context of Environmental Degradation: Building or Crumbling
} 
Adaptation Strategies' (forthcoming 2016). The author is grateful for the invaluable comments of Dr Edwini Kessie.

${ }^{2}$ W. Kälin and N. Schrepfer, 'Protecting People Crossing Borders in the Context of Climate Change Normative Gaps and Possible Approaches', UNHCR Legal and Protection Policy Research Series (2012); Special Rapporteur on the Human Rights of Migrants, Human Rights of Migrants, UNGA A/67/299 (13 August 2012).

${ }^{3}$ IPCCC, IPCC's Working Group II contribution to the Fifth Assessment Report, March 2014 <www.ipcc.ch/report/ar5/wg2> accessed 25 October 2016.

${ }^{4}$ International Organization of Migration (IOM), 'Moving in the Right Direction? Assessing Progress in Doha: Migration in climate change negotiations', IOM Migration Policy Brief (2013).

${ }^{5}$ The Conference of the Parties (COP), at its nineteenth session, established the Warsaw International Mechanism to address loss and damage associated with the adverse effects of climate change. The COP, in para. 49 of the Decision 1/CP.21 (2015), requested the Executive Committee of the Warsaw International Mechanism to establish, according to its procedures and mandate, a task force to complement, draw upon the work of and involve, as appropriate, existing bodies and expert groups under the Convention including the Adaptation Committee and the Least Developed Countries Expert Group, as well as relevant organisations and expert bodies outside the Convention, to develop recommendations for integrated approaches to avert, minimise and address displacement related to the adverse impacts of climate change. Conference of the Parties, twenty first session, Agenda item 4b, Durban Platform for Enhanced Action (decision 1/CP/17) Adoption of a protocol, another legal instrument, or an agreed outcome with legal force under the Convention applicable to all parties (FCCC/CP/2015/L.9/Rev.1), 12 December 2015.

${ }^{6}$ The Nansen Initiative was conceived as 'a state-led consultative process to build consensus on a protection agenda addressing the needs of people displaced across borders in the context of disasters and the effects of climate change.' This process started in 2012 and ended in 2015 with the adoption of the 'Protection Agenda.'

${ }^{7}$ W. Kälin, 'From the Nansen Principles to the Nansen Initiative' (2012) 41 Forced Migration Review.

${ }^{8}$ The Nansen Initiative, Agenda for the Protection of Cross-Border Displacement in the Context of Disasters and Climate Change: A Protection Agenda, Volume I (2015).

${ }^{9}$ European Commission (EC), Communication from the Commission to the European Parliament, the Council, the European Economic and Social Committee and the Committee of the Regions: An EU Strategy on Adaptation to Climate Change, Brussels, 16 April 2013, COM (2013) 216 final; International Centre for Migration Policy Development (ICMPD), "Climate Refugees" Legal and Political Responses to Environmentally Induced Migration,' Study, Directorate-General for Internal Policies, Policy Department Citizens' Rights and Constitutional Affairs C, Brussels (2011).

${ }^{10}$ Advisory Group, Human Mobility in the Context of Climate Change, recommendations from the Advisory Group on climate change and human mobility COP 20, Lima, Peru, 2015, 9.

${ }^{11}$ ibid.

${ }^{12}$ Foresight, Migration and Global Environmental Change, Future Challenges and Opportunities, Final Project Report, The Government Office for Science, London (2011); R. McLeman and B. Smit, Climate Change and Human Migration: Past Experiences, Future Challenges (Cambridge University Press 2014); D. Ionesco, D. Mokhnacheva and F. Gemenne, Atlas des migrations environnementales (Presse de Science Po 2016).

${ }^{13}$ In this chapter we follow the definition adopted by the Nansen Initiative for 'migration and adaptation', as 'the voluntary decision to avoid or to adjust to deteriorating environmental conditions that could otherwise result in a humanitarian crisis or displacement in the future.' Nansen Initiative (n.8) para.25.

${ }^{14}$ G. Bettini, S. Nash and G. Gioli, 'One Step Forward, Two Steps Back? The Fading Contours of (In)Justice in Competing Discourses on Climate Migration' (September 2016) 183(3) The Geographical Journal.

${ }^{15}$ International Organization for Migration (IOM), 'Climate Change, Environmental Degradation and Migration’, International Dialogue on Migration, No.18, Geneva (2012). 
${ }^{16}$ EC, Communication from the Commission (n.9); ICMPD, 'Climate Refugees' (n.9).

${ }^{17}$ J. McAdam, Climate Change and International Law (Oxford University Press 2012).

${ }^{18}$ Kälin, 'Nansen Principles' (n.7).

${ }^{19}$ Advisory Group, Human Mobility (n.10) 5

${ }^{20}$ Ibid.

${ }^{21}$ Bettini, Nash and Gioli, 'One Step Forward, Two Steps Back' (n.14).

${ }^{22}$ Ibid.

${ }^{23}$ Ibid.

${ }^{24}$ F. Gemenne and J. Blocher, 'How Can Migration Support Adaptation? Different Options to Test the Migration-adaptation Nexus', paper presented at the COST Workshop on Environmental Migration, World Trade Institute, October 2014; C. Methmann and A. Oels, "From "Fearing" to Empowering Climate Refugees: Governing Climate-induced Migration in the Name of Resilience' (2015) 46(I) Security Dialogue 51-68.

${ }^{25}$ G. Bettini and G. Gioli, 'Waltz with Development: Insights on the Developmentalization of Climate-induced Migration' (2016) 5 Migration and Development 171-189; B. Burson and R. Bedford, Opportunities and Challenges in Facilitating Voluntary Adaptive Migration in the Pacific in the Context of Climate Change, Submission to the Executive Committee of the Warsaw International Mechanism for loss and damage associated with climate change impacts (2016).

${ }^{26}$ A. Baldwin, 'Pluralizing Climate Change and Migration: An Argument in Favour of Open Futures' (2014) 8(8) Geography Compass 516-528; R. Felli, 'Managing Insecurity by Ensuring Continous Capital Accumulation: "Climate Refugees" and "Climate Migrants" (2013) 18(3) New Political Economy 337-363.

${ }^{27}$ Baldwin, ibid 520. Methmann and Oels, 'From "Fearing" to Empowering' (n.24); K. Ober, Migration as Adaptation: Exploring Mobility as a Coping Strategy for Climate Change, UK Climate Change and Migration Coalition (2015).

${ }^{28}$ The Pacific Island Countries are comprised of 22 states and territories, namely: the Federated States of Micronesia, Fiji, French Polynesia, Guam, Kiribati, Marshall Islands, American Samoa, the Cook Islands, Tokelau, Tuvalu, Vanuatu, the Solomon Islands, Tonga, Papua New Guinea, Pitcairn Islands, Nauru, Niue, Northern Mariana Islands, Palau, and Wallis and Futuna.

${ }^{29}$ International Labour Organization (ILO), Decent Work and Social Justice in Pacific Small Island Developing States Challenges, Opportunities and Policy Responses (2014).

${ }^{30}$ S. Kagan, 'Making the Case for Preferential Access to Labour Markets for Kiribati and Tuvalu Migrants' 20 January 2015 〈http://devpolicy.org/making-the-case-for-preferential-access-to-labourmarkets-for-kiribati-and-tuvalu-migrants-20140120/> accessed 25 October 2016; ILO, Kiribati National Labour Migration Policy, Report (25 November 2015); ILO, Tuvalu National Labour Migration Policy, Ministry of Foreign Affairs, Trade, Tourism, Environment and Labour, Report (24 November 2015).

${ }^{31}$ W. Eberhard, 'Of Tsunamis and Climate Change: The Need to Resettle? The Pacific Islands', paper presented at the European Science Foundation Conference 'Tracing Social Inequalities in Environmentally-Induced Migration', University of Bielefeld, 9-13 December 2012.

${ }^{32}$ ILO, Decent Work and Social Justice (n.29).

${ }^{33}$ R. Bedford, B. Burson and C. Bedford, Compendium of Legislation and Institutional Arrangements for Labour Migration in the Pacific Island Countries, International Labour Organization (2014).

${ }^{34}$ Kagan, 'Making the Case for Preferential Access' (n.30).

${ }^{35}$ ILO, Decent Work and Social Justice (n.29) 18.

${ }^{36}$ ILO, Kiribati National Labour Migration Policy (n.30); ILO, Tuvalu National Labour Migration Policy (n.30); World Bank, Well-being from Work in the Pacific Island Countries, The World Bank, Washington DC (2014).

${ }^{37}$ ILO, Decent Work and Social Justice (n.29).

${ }^{38}$ Ibid.

${ }^{39}$ P. Martin, 'Low Skilled Labour Migration and Free Trade Agreements', in M. Panizzon, G. Zuercher, E. Fornalé (eds.), The Palgrave Handbook of International Labour Mobility (Palgrave 2015) 205. 
${ }^{40}$ Ibid 206.

${ }^{41}$ New Zealand Department of Labour, Recognised Seasonal Employer: Interagency Understanding: Vanuatu, New Zealand Department of Labour and Republic of Vanuatu Ministry of Internal Affairs, 2007.

${ }^{42}$ World Bank, Well-being from Work (n.36).

${ }^{43}$ B. Burson and R. Bedford, 'Clusters and Hubs: Toward a Regional Architecture for Voluntary Adaptive Migration in the Pacific', discussion paper, 9 December 2013, the Nansen Initiative.

${ }^{44}$ R. Curtain et al, Pacific Possible, Labour Mobility: The Ten Billion Dollar Prize, World Bank (July 2016).

45 J. Gibson and D. Mckenzie, Australia's Pacific Seasonal Workers Pilot Scheme (PSWPS): Development Impacts in the First Two Years $<$ http://siteresources.worldbank.org/DEC/Resources/Australia Pacific Seasional Worker Pilot Sche me.pdf> accessed 25 October 2016.

${ }^{46}$ World Bank, Well-being from Work (n.36).

${ }^{47}$ D. McKenzie, P. Garcia Martinez and L. Alan Winters, Who is Coming from Vanuatu to New Zealand Under the New Recognised Seasonal Employer Programme, The World Bank Development Research Group Finance and Private Sector Team (2008).

${ }^{48}$ D. Hay and S. Howes, Australia's Pacific Seasonal Worker Pilot Scheme: Why Has Take-Up Been So Low? (2012) Discussion Paper No.17, Development Policy Centre, Australian National University. 49 'Labour Mobility Workshop', 26-27 September 2014, Auckland, New Zealand.

${ }^{50}$ Commonwealth of Australia, Our North, Our Future: White Paper on Developing Northern Australia (2015) <http://industry.gov.au/ONA/WhitePaper/index.html> accessed 25 October 2016.

${ }^{51}$ McKenzie, Garcia Martinez, Alan Winters (n.47) 27.

${ }^{52}$ World Bank, Well-being from Work (n.36); F. Thornton, 'Regional Labour Migration as Adaptation to Climate Change? Options in the Pacific', in M. Leighton, S. Xiaomeng and K. Warner (eds.), Climate Change and Migration: Rethinking Policies for Adaptation and Disaster Risk Reduction, SOURCE, No.15 (2011).

${ }^{53}$ M. Becker, 'The Discourse about Legal Protection for Environmental Refugees: Re-constructing Categories - Rethinking Policies', in F. Gesing, J. Herbeck and S. Klepp, Denaturalizing Climate Change: Migration, Mobilities and Space, ARTEC Paper 200 (December 2014).

${ }^{54}$ In 1981 PICs concluded a regional trade agreement with Australia and New Zealand, the South Pacific Regional Trade and Economic Cooperation Agreement (SPARTECA).

${ }^{55}$ D. Ritter, 'Climate Change and Human Rights: The Imperative for Climate Change Migration with Dignity (CCMD)' in M. Di Paola and D. Kamal (eds), Climate Change and Human Rights: The 2015 Paris Conference and the Task of Protecting People on a Warming Planet, Global Policy, November 2015.

${ }^{56}$ ILO, Decent Work and Social Justice (n.29) 22.

${ }^{57}$ Pacific Islands Forum Secretariat, Pacific Island Countries Trade Agreement (PICTA) Temporary Movement of Persons, Labour Mobility Workshop, Auckland, New Zealand (September 2014).

${ }^{58}$ Office of the Chief Adviser (OCTA), NSAs Workshop on the PACER Plus Negotiations, Nadi, Fiji, 2014.

59 F. Chaudharym, 'PACER Plus Concerns', Fiji Times, 23 June 2016 $<$ www.fijitimes.com/story.aspx ?id=359342> accessed 25 October 2016.

60 'OCTA Presentations During the Sixth Non-State Actors Dialogue Workshop on PACER Plus 2016 ' <www.octapic.org/wp-content/uploads/2016/06/Labour-Mobility-.pdf> accessed 25 October 2016.

${ }^{61}$ J. Kelsey, New Zealand's Commitments on Trade in Services and Labour Mobility, Pacific Network on Globalisation (2009).

62 See: <www.mfat.govt.nz/en/trade/free-trade-agreements/free-trade-agreements-in-force/aanzftaasean-australia-new-zealand-fta/> accessed 25 October 2016.

${ }^{63}$ See: 〈www.mfat.govt.nz/en/trade/free-trade-agreements/free-trade-agreements-in-force/china-fta/> accessed 25 October 2016.

${ }^{64}$ The Protocol has been signed by Kiribati, Nauru, Samoa, Solomon Islands, Tonga, Tuvalu, Vanuatu 
and the Federated States of Micronesia.

${ }^{65}$ Tier 1 covers professionals who have a bachelor's degree and appropriate working experience, and Tier 2 covers semi-skilled professionals who have a diploma or certificate. Observatory on Migration (ACP), South-South Labour Mobility in the Pacific: An Overview (2013) 23.

${ }^{66}$ Ibid.

${ }^{67}$ Ibid 22.

${ }^{68}$ Ibid.

${ }^{69}$ The Melanesian Spearhead Group (MSG) originated in 1980 after the end of the Anglo-French Condominium. The MSG included Papua New Guinea, Solomon Islands, Vanuatu and Fiji, and a political party in the French colony of New Caledonia (Le Front de Liberation Nationale Kanak et Socialiste or FLNKS).

${ }^{70}$ ACP, South-South Labour Mobility (n.65) 24.

${ }^{71}$ Ibid 33.

${ }^{72}$ Ibid. 